\title{
A practical method of measuring oxygen consumption in children with complex mixing circulations by the use of thermodilution cardiac output studies
}

Daryl I. Schantz, MD, and Robert P. Chen, MD

Objective: We describe a method to measure oxygen consumption $\left(\mathrm{VO}_{2}\right)$ and pulmonary vascular resistive index (PVRI) based on thermodilution cardiac output in patients with complex mixing circulations. We apply this method to patients with a bidirectional cavopulmonary anastomosis (BDCPA). We compare our measured $\mathrm{VO}_{2}$ with a predicted $\mathrm{VO}_{2}$ based on a formula using height and weight.

Methods: We reviewed data based on cardiac catheterization and thermodilution cardiac output in a series of 25 catheterizations in patients with BDCPA. We used this data to measure $\mathrm{VO}_{2}$ and PVRI, and looked for a correlation between the predicted and measured $\mathrm{VO}_{2}$. We also assessed whether any other hemodynamic parameter correlated with measured $\mathrm{VO}_{2}$.

Results: There was no significant correlation between the predicted and the measured $\mathrm{VO}_{2}$ (correlation coefficient $=-0.258, P=.21$ ). We did find a significant correlation in the difference between the measured and predicted $\mathrm{VO}_{2}$ against the measured $\mathrm{VO}_{2}$ such that at a lower measured $\mathrm{VO}_{2}$ the predictive formula tended to overestimate $\mathrm{VO}_{2}$ and at a higher $\mathrm{VO}_{2}$ the formula underestimated $\mathrm{VO}_{2}$ (correlation coefficient $=0.963$, $P<.0001$ ). Body surface area did not correlate with measured $\mathrm{VO}_{2}$ (correlation coefficient $=0.28, P<.16$ ). Mixed venous oxygen content showed a weak negative correlation with $\mathrm{VO}_{2}$ (correlation coefficient $=-0.54$, $P=.005)$.

Conclusions: An assessment of PVRI that is based on a predicted $\mathrm{VO}_{2}$ is unreliable in this patient population. No hemodynamic parameter correlated well with $\mathrm{VO}_{2}$. The use of a measured $\mathrm{VO}_{2}$ is necessary in determining PVRI in these patients. (J Thorac Cardiovasc Surg 2013;146:1179-84)

The assessment of pulmonary blood flow and pulmonary vascular resistance (PVR) in complex mixing circulations is challenging. Still, this assessment remains an important aspect in risk stratification prior to staged surgical palliation via bidirectional cavopulmonary anastomosis (BDCPA) and the Fontan procedure. Typically, this assessment is done by combining cardiac catheterization data with the use of a predicted oxygen consumption $\left(\mathrm{VO}_{2}\right)$ from one of several predictive formulas because methods of direct measurement of $\mathrm{VO}_{2}$ are complicated and require expensive equipment and operator expertise.

We report a previously undescribed method of calculating PVR and $\mathrm{VO}_{2}$. We compare this measured $\mathrm{VO}_{2}$ with a standard predicted $\mathrm{VO}_{2}$ based on the formula described by Krovets and Goldbloom. ${ }^{1}$ We demonstrate how we can calculate PVR based on thermodilution cardiac output

\footnotetext{
From the Department of Pediatric Cardiology, Dalhousie University, Halifax, Nova Scotia, Canada.

Disclosures: Authors have nothing to disclose with regard to commercial support. Received for publication March 10, 2012; revisions received Sept 6, 2012; accepted for publication Sept 21, 2012; available ahead of print Feb 4, 2013.

Address for reprints: Robert P. Chen, MD, IWK Children's Heart Centre, 5850

University Ave, Halifax, Nova Scotia, Canada B3K 6R8 (E-mail: Robert.Chen@ iwk.nshealth.ca).

$0022-5223 / \$ 36.00$

Copyright (c) 2013 by The American Association for Thoracic Surgery

http://dx.doi.org/10.1016/j.jtcvs.2012.09.103
}

studies in patients with BDCPA. This method can be used in many complex mixing circulations to calculate flows and resistances in the systemic or pulmonary vascular beds. We examined hemodynamic parameters that might predict $\mathrm{VO}_{2}$ in BDCPA.

\section{METHODS}

\section{Assessing the Pulmonary Vascular Resistive Index (PVRI)}

Assessment of PVR in a normal circulation is based on the application of Ohm's law:

$$
\mathrm{PVR}=\Delta \mathrm{P} / \mathrm{Q}_{\mathrm{P}},
$$

where $\mathrm{R}$ is resistance, $\Delta \mathrm{P}$ is the mean transpulmonary pressure gradient, and $\mathrm{Q}_{\mathrm{P}}$ is pulmonary blood flow.

Pressure is obtained by direct measurement. Pulmonary blood flow equals $\mathrm{VO}_{2}$ divided by the difference in oxygen content please insert " $\left(\mathrm{cO}_{2}\right)$ " in the pulmonary veins and in the main pulmonary artery:

$$
\mathrm{Q}_{\mathrm{P}}=\mathrm{VO}_{2} /\left(\mathrm{cO}_{2 \mathrm{PV}}-\mathrm{cO}_{2} \mathrm{PA}\right),
$$

where $\mathrm{cO}_{2}$ is the content of oxygen, $\mathrm{PV}$ is the pulmonary vein, and $\mathrm{PA}$ is the pulmonary artery.

$\mathrm{VO}_{2}$ can be measured using indirect calorimetry with a Douglas bag, or with tandem mass spectrometry. These methods measure the inspired and expired oxygen content directly, but they are time-consuming, and many centers do not have tandem mass spectrometry to perform such measurements. Oxygen consumption can also be predicted using one of a number of formulas, including those by Lafarge and Miettinen, ${ }^{2}$ Lundell and 


$\begin{array}{ll}\text { Abbreviations and Acronyms } \\ \mathrm{Ao} \quad=\text { aortic } \\ \mathrm{APC} & =\text { aortopulmonary collateral } \\ \mathrm{BDCPA} & =\text { bidirectional cavopulmonary } \\ & \text { anastomosis } \\ \mathrm{BSA} & =\text { body surface area } \\ \mathrm{cO}_{2} & =\text { content of oxygen } \\ \Delta \mathrm{P} & =\text { mean transpulmonary pressure gradient } \\ \mathrm{IVC} & =\text { inferior vena cava } \\ \mathrm{MRI} & =\text { magnetic resonance imaging } \\ \mathrm{RA} & =\text { right atrium } \\ \mathrm{PA} & =\text { pulmonary artery } \\ \mathrm{PV} & =\text { pulmonary vein } \\ \mathrm{PVR} & =\text { pulmonary vascular resistance } \\ \mathrm{PVRI} & =\text { pulmonary vascular resistive index } \\ \mathrm{Q}_{\mathrm{P}} & \text { pulmonary blood flow } \\ \mathrm{Q}_{\mathrm{S}} & =\text { cardiac output } \\ \mathrm{Q}_{\mathrm{V}} & =\text { systemic ventricular output } \\ \mathrm{SVC} & =\text { superior vena cava } \\ \mathrm{VcO}_{2} & =\text { minute oxygen delivery } \\ \mathrm{VO}_{2} & =\text { oxygen consumption }\end{array}$

colleagues, ${ }^{3}$ Lindahl, ${ }^{4}$ Wessel and associates, ${ }^{5}$ and Krovets and Goldbloom. ${ }^{1}$ A predictive formula for $\mathrm{VO}_{2}$ does not require complex measurements, which makes them an attractive solution for obtaining $\mathrm{VO}_{2}$. However, it has been shown that these formulas are unreliable when compared with measured $\mathrm{VO}_{2}$ in children with congenital heart defects.

Laitinen and Rasanen, ${ }^{6}$ who compared the formulas by Lindahl, ${ }^{4}$ Wessel and associates, ${ }^{5}$ Lundell and colleagues, ${ }^{3}$ against indirect calorimetry, and $\mathrm{Li}$ and coworkers, ${ }^{7}$ who compared the same formulas as well as the formula published by Lafarge and Miettinen ${ }^{2}$ against respiratory mass spectrometry in children with congenital heart disease found the predictive formulas to be unreliable. In the latter study, the predictive formulas were found to overestimate lower and underestimate higher indexed $\mathrm{VO}_{2}$. Likewise, Shanahan and colleagues ${ }^{8}$ compared the predictive formulas by Lindahl, ${ }^{4}$ Lundell and colleagues, ${ }^{3}$ and Lafarge and Miettinen ${ }^{2}$ against indirect calorimetry in 35 patients with a BDCPA. They found that the formulas overestimated $\mathrm{VO}_{2}$ in their patients and led to an underestimation of PVR, resulting in errors in risk stratification for these patients.

\section{Minute Oxygen Delivery}

The search for a simple, noninvasive measurement of cardiac output is ongoing. ${ }^{9}$ Invasive measurement by thermodilution studies are possible and require little additional time or expense for patients who are undergoing planned cardiac catheterization. Thermodilution-derived measurements of cardiac output have generally been found to have good agreement compared with Fick-derived measurements of cardiac output. ${ }^{9-11}$

In simple circulations without intracardiac shunts, it is possible to measure cardiac output with thermodilution studies. In this case, pulmonary blood flow is equal to cardiac output $\left(\mathrm{Q}_{\mathrm{P}}=\mathrm{Q}_{\mathrm{S}}\right)$; therefore, $\mathrm{Q}_{\mathrm{P}}$ is measured directly and PVR can be solved without measuring $\mathrm{VO}_{2}$. In this circumstance, $\mathrm{VO}_{2}$ can be calculated using the Fick principle:

$$
\mathrm{VO}_{2}=\mathrm{Q}_{\mathrm{P}} \times\left(\mathrm{cO}_{2} \mathrm{PV}-\mathrm{cO}_{2} \mathrm{PA}\right)
$$

In BDCPA, it is possible to measure systemic ventricular output $\left(\mathrm{Q}_{\mathrm{V}}\right)$ using thermodilution cardiac output studies, but $\mathrm{Q}_{\mathrm{V}}$ is not equal to $\mathrm{Q}_{\mathrm{P}}$. To resolve this problem, we introduce the concept of minute oxygen delivery $\left(\mathrm{VcO}_{2}\right)$.

Oxygen contents and saturations are not additive. In the case of a BDCPA, it is not possible to calculate the aortic (Ao) $\mathrm{cO}_{2}$ or saturation based on the oxygen contents and saturations in the right atrium (RA) and PVs. Oxygen content in the aorta depends on both the flow and the $\mathrm{cO}_{2}$ from each of the sources. If we multiply the $\mathrm{cO}_{2}$ in a vessel (measured in $\mathrm{mL} / \mathrm{L}$ ) by the flow through the vessel (measured in $\mathrm{L} / \mathrm{min}$ ), we obtain the $\mathrm{VcO}_{2}$ through the vessel (measured in $\mathrm{mL} \mathrm{O}_{2} / \mathrm{min}$ ). We designate this minute oxygen delivery as $\mathrm{VcO}_{2}$.

Therefore, in a BDCPA, where $\mathrm{U}$ is upper body, $\mathrm{L}$ is upper body, $\mathrm{Q}_{\mathrm{EP}}$ is effective pulmonary blood flow, $\mathrm{x}$ is the thermodilution measurement.

$$
\begin{aligned}
& \mathrm{VcO}_{2}{ }_{\text {Ao }}=\mathrm{VcO}_{2} \mathrm{PV}+\mathrm{VcO}_{2} \mathrm{RA} \\
& \mathbf{Q}_{\mathbf{V}}=\mathbf{Q}_{\mathbf{U}}+\mathbf{Q}_{\mathbf{L}} \\
& \mathbf{Q}_{\mathbf{U}}=\mathbf{Q}_{\mathbf{E P}} \\
& \mathrm{Q}_{\mathrm{V}}=\mathrm{Q}_{\mathrm{EP}}+\mathrm{Q}_{\mathrm{L}} \\
& \mathrm{Q}_{\mathrm{L}}=\mathrm{Q}_{\mathrm{V}}-\mathrm{Q}_{\mathrm{EP}} \\
& \mathbf{Q}_{\mathbf{v}}=x \\
& \mathrm{Q}_{\mathrm{V}} \times \mathrm{cO}_{2 \mathrm{AO}}=\mathrm{Q}_{\mathrm{EP}} \times \mathrm{cO}_{2 \mathrm{PV}}+\mathrm{Q}_{\mathrm{L}} \times \mathrm{cO}_{2 \mathrm{RA}} \\
& \mathrm{Q}_{\mathrm{V}} \times \mathrm{cO}_{2 \mathrm{AO}}=\mathrm{Q}_{\mathrm{EP}} \times \mathrm{cO}_{2 \mathrm{PV}}+\left(\mathrm{Q}_{\mathrm{V}}-\mathrm{Q}_{\mathrm{EP}}\right) \times \mathrm{cO}_{2 \mathrm{RA}} \\
& \mathrm{Q}_{\mathrm{EP}}=\frac{x \times\left(\mathrm{CO}_{2 \mathrm{AO}}-\mathrm{cO}_{2 \mathrm{RA}}\right)}{\left(\mathrm{cO}_{2 \mathrm{PV}}-\mathrm{cO}_{2 \mathrm{RA}}\right)}
\end{aligned}
$$

Then,

$$
\begin{aligned}
& \mathrm{Q}_{\mathrm{EP}}=\frac{\mathrm{VO}_{2}}{\left(\mathrm{cO}_{2 \mathrm{PV}}-\mathrm{cO}_{2 \mathrm{PA}}\right)} \\
& \mathrm{VO}_{2}=\frac{\mathbf{x} \times\left(\mathrm{CO}_{2 \mathrm{AO}}-\mathrm{cO}_{2 \mathrm{RA}}\right) \times\left(\mathrm{cO}_{2 \mathrm{PV}}-\mathrm{cO}_{2} \mathrm{PA}\right)}{\left(\mathrm{cO}_{2} \mathrm{PV}-\mathrm{cO}_{2 \mathrm{RA}}\right)}
\end{aligned}
$$

Using this method, certain considerations apply to the collection and interpretation of samples during the cardiac catheterization. There should be no competitive blood flow into the PA, including large aortopulmonary collaterals (APCs) or antegrade flow through a patent pulmonary valve. Right atrial blood sampling should be done near the RA-inferior vena cava (IVC) junction to minimize admixture from the PVs, but still allow adequate mixture of blood from the lower body. The PV sample ideally should contain mixed PV blood, but not contain admixture from the IVC.

\section{Subjects}

We gathered data prospectively from cardiac catheterizations done in patients with BDCPA from September 2000 to March 2009. We included data sets from multiple catheterizations in the same patient as long as they were done $>12$ months apart. We excluded those patients with competitive blood supply from the PA when it had not been ligated, such as patients with tricuspid atresia who still had antegrade flow through the pulmonary valve.

\section{Catheterization Procedure}

All catheterizations were done under general anesthesia with mechanical, positive-pressure ventilation. Hemodynamic data were collected at the 
beginning of the catheterization followed by thermodilution cardiac output studies and prior to any angiography. A thermodilution catheter was used to inject room-temperature saline into the IVC or RA with the thermistor in the ascending aorta. We repeated injections until we had 3 samples that were within $10 \%$, and used the averaged value for cardiac output.

Measured $\mathrm{VO}_{2}$ and PVR were determined using the method described earlier. Predicted $\mathrm{VO}_{2}$ was calculated using the formula by Krovetz and Goldbloom ${ }^{1}$ :

$$
\mathrm{VO}_{2}=1.39 \times \text { Height }+0.84 \times \text { Weight }-35.7,
$$

where height is measured in centimeters and weight is measured in kilograms.

\section{Data Analysis}

We looked for correlation between measured and predicted $\mathrm{VO}_{2}$ (indexed and nonindexed). We also looked for correlation between the difference in the predicted and measured $\mathrm{VO}_{2}$ against the measured $\mathrm{VO}_{2}$. Last, we looked for correlations between patient variables such as height, weight, and body surface area (BSA) as well as hemodynamic parameters including $\mathrm{cO}_{2}$ and mean pressures throughout the circulation against the measured $\mathrm{VO}_{2}$. We evaluated whether there was a parameter that could be a surrogate for $\mathrm{VO}_{2}$ measurement with thermodilution cardiac output.

We used the Pearson 2-tailed test to look for correlation coefficients between variables. Results were considered statistically significant if the $P$ value was $<.05$.

This study was done with the approval of the research ethics board at the IWK Health Centre. Because of the nature of the study, the requirement for informed consent was waived.

\section{RESULTS}

Twenty-seven catheterizations were included. Two patients were excluded from the analysis because of competitive pulmonary blood flow via a patent pulmonary valve. This left 25 catheterizations from 21 patients. The age range was 1.3 to 10 years of age at the time of cardiac catheterization, with a median age of 2.9 years.

The systemic ventricle was the morphologically right ventricle in 11 patients $(52 \%)$ and the morphologically left ventricle in 10 patients $(48 \%)$. The underlying cardiac malformation was pulmonary atresia with intact ventricular septum in 3 patients $(14 \%)$, double-inlet left ventricle in 7 patients $(33 \%)$, atrioventricular septal defect in 2 patients $(10 \%)$, hypoplastic left heart syndrome in 6 patients $(29 \%)$, and dextrocardia, atrioventricular septal defect with heterotaxy in 3 patients $(14 \%)$.

Fifteen of 21 patients $(67 \%)$ had collateralization identified at the time of cardiac catheterization. Nine patients $(43 \%)$ had APCs and 10 patients $(48 \%)$ had venovenous collaterals, with 4 patients having both APCs and venovenous collaterals. The majority of these were hemodynamically insignificant or were venovenous and did not contribute to any unmeasured shunt. Two patients underwent coil occlusion of collateral vessels; one was a small, left-sided superior vena cava (SVC) and the other was a large APC off of an internal mammary artery.

We found there was no correlation between the predicted $\mathrm{VO}_{2}$ and the measured $\mathrm{VO}_{2}$ (correlation

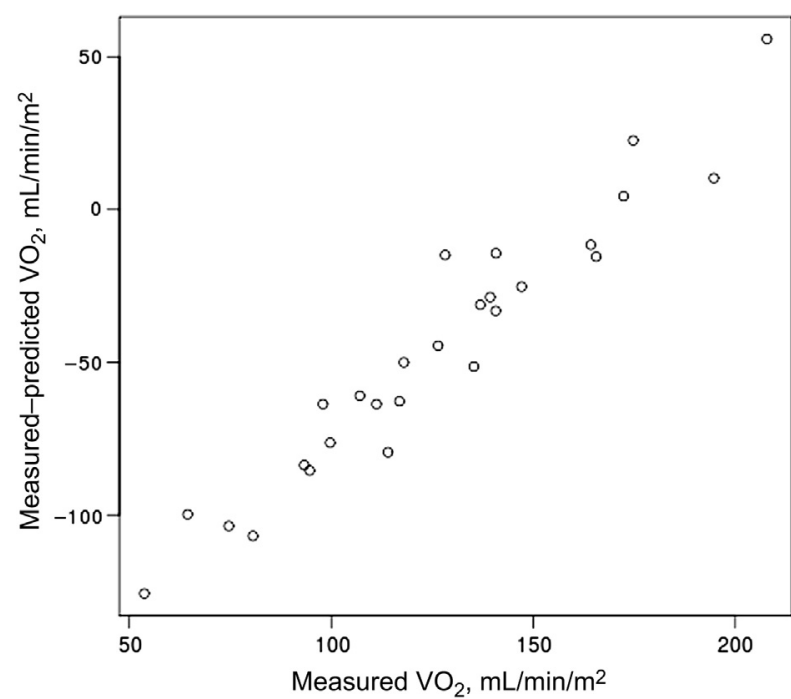

FIGURE 1. The relationship between the difference in measured and predicted oxygen consumption $\left(\mathrm{VO}_{2}\right)$ against predicted $\mathrm{VO}_{2}$. No difference would be represented as a horizontal scattering around 0 (Pearson correlation coefficient $=0.96, P<.001)$.

coefficient $=-0.26, P=.21)$. We did find correlation between the difference in the predicted and the measured $\mathrm{VO}_{2}$ compared with the measured $\mathrm{VO}_{2}$ (Figure 1). The Krovets and Goldbloom ${ }^{1}$ equation increasingly overestimated $\mathrm{VO}_{2}$ as the measured $\mathrm{VO}_{2}$ diminished. An overestimation of $\mathrm{VO}_{2}$ results in an underestimation in PVR.

There were no hemodynamic parameters that were a good substitute for measuring $\mathrm{VO}_{2}$. We did see a weak, but significantly negative, correlation between the $\mathrm{cO}_{2}$ in the RA and the SVC against the $\mathrm{VO}_{2}$ (Table 1). We found that as $\mathrm{VO}_{2}$ increased, the systemic venous $\mathrm{cO}_{2}$ decreased.

As expected, there is a high correlation between the Krovets and Goldbloom ${ }^{1}$ predicted $\mathrm{VO}_{2}$ and BSA (correlation coefficient $=0.96, P<.001$ ), because this value is calculated from the same parameters as BSA. However, our measured $\mathrm{VO}_{2}$ from thermodilution cardiac output

TABLE 1. Correlation between hemodynamic parameters and indexed $\mathrm{VO}_{2}$

\begin{tabular}{lc}
\hline Variable & Pearson correlation coefficient $(\boldsymbol{P}$ value $)$ \\
\hline $\mathrm{QV}_{\mathrm{V}}$ & $-0.09(.65)$ \\
$\mathrm{Q}_{\mathrm{V}}$, indexed & $0.16(.42)$ \\
$\mathrm{TcO}_{2} \mathrm{RA}$ & $-0.54(.005)$ \\
$\mathrm{TcO}_{2} \mathrm{PV}$ & $-0.37(.07)$ \\
$\mathrm{TcO}_{2} \mathrm{SVC}$ & $-0.39(.049)$ \\
$\mathrm{TcO}_{2}$ Ao & $-0.37(.07)$ \\
$\mathrm{RAP}$ & $-0.02(.9)$ \\
$\mathrm{mPAP}$ & $0.04(.85)$ \\
$\mathrm{V}_{\mathrm{EDP}}$ & $0.07(.72)$ \\
\hline$Q_{\mathrm{V}} \mathrm{The}$
\end{tabular}

$Q_{V}$, Thermodilution cardiac output; $\mathrm{Tc}_{2}$, total content of oxygen; $\mathrm{RA}$, right atrium; $P V$, pulmonary vein; $S V C$, superior vena cava; $A o$, aorta; $m P A P$, mean pulmonary arterial pressure; $V_{E D P}$, ventricular end diastolic pressure. 


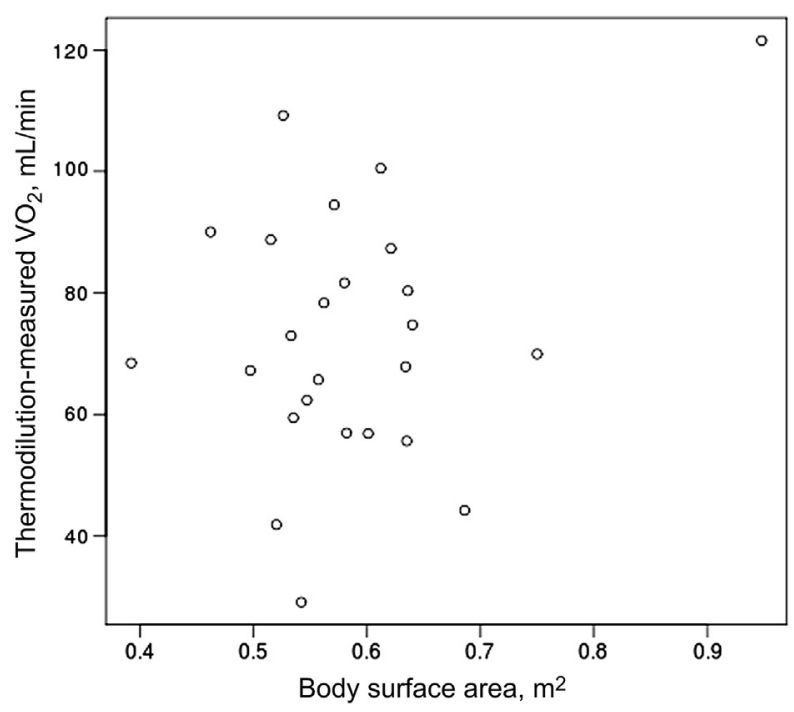

FIGURE 2. There was no correlation between body surface area and measured oxygen consumption (Pearson correlation coefficient $=-0.02$, $P=.211)$.

measurement did not correlate with BSA at all (correlation coefficient $=0.28, P<.16$; Figure 2 ).

\section{DISCUSSION}

The Fontan operation is the final stage in a series of operations creating a circuit to route systemic venous return passively to the PAs, so a single ventricle provides systemic output. It is used to palliate a number of complex congenital heart defects in which a biventricular circulation cannot be attained.

The Fontan operation is preceded by a BDCPA in which the SVC is connected to the PAs. Choussat and Fontan outlined 10 criteria, which have become known as the 10 Commandments, to ensure a good outcome for the Fontan procedure. ${ }^{12}$ These are essentially a mean pulmonary arterial pressure of $<15$ to $20 \mathrm{~mm} \mathrm{Hg}$ and a normal PVRI. ${ }^{13,14}$

There has been controversy over the necessity of cardiac catheterization for risk assessment prior to the Fontan procedure with the availability of magnetic resonance imaging (MRI) to provide good anatomic assessment of cardiac and pulmonary arterial anatomy. ${ }^{15,16}$ However, catheterization remains the only way to assess PVRI, pulmonary arterial pressure, transpulmonary gradient, and ventricular end diastolic pressure, which are all predictive of outcome.

Mair and colleagues ${ }^{17}$ developed an index based on PVR and ventricular end diastolic pressure. They evaluated this index as a predictor of mortality in children with tricuspid atresia undergoing the Fontan procedure. They found an index of $<4$ was associated with an $8 \%$ late mortality whereas an index $>4$ was associated with a late mortality of $39 \%$.

Pizzaro and associates ${ }^{18}$ reported the outcomes of their patient population of 107 children aged 11 to 35 months undergoing the Fontan procedure with both single right and single left ventricular anatomy. They reported a transpulmonary gradient of $7.2 \pm 1.5 \mathrm{~mm} \mathrm{Hg}$ in those who died compared with $5.3 \pm 1.9(P=.03)$ in survivors. Elevated pulmonary arterial pressures also predicted a higher likelihood of Fontan takedown.

Malhotra and coworkers ${ }^{19}$ reviewed the results of 52 Fontan procedures in patients with systemic left or right ventricles. They found that an elevated PVRI was predictive of Fontan failure resulting in death, revision or takedown of the Fontan, or cardiac transplant. The PVRI in the group that failed with the Fontan procedure was $2.43 \pm 1.01$ Woods units, which is significantly higher than the overall group $(1.95 \pm 1.42[P=.007])$. This study was performed in Denver, Colorado, with patients living at high altitudes. Therefore, although the finding of an increased PVRI in this group is important, the specific PVRI probably cannot be generalized to other populations. Other authors have found increased PVR to correlate with longer duration of pleural effusion. ${ }^{20}$

Our data confirm that using an estimated $\mathrm{VO}_{2}$ for calculation of PVR introduces error. The majority of our patients had a measured $\mathrm{VO}_{2}$ that was lower than their predicted $\mathrm{VO}_{2}$. Because all our patients were about the same age at the time of their catheterizations, the predicted $\mathrm{VO}_{2}$ based on the Krovetz and Goldbloom ${ }^{1}$ formula tended to be very similar between patients. This explains why there was a nearly linear relationship between the difference in predicted and measure $\mathrm{VO}_{2}$ versus the measured $\mathrm{VO}_{2}$.

As seen in Figure 1, the predicted $\mathrm{VO}_{2}$ was almost always greater than the measured $\mathrm{VO}_{2}$. Because the calculation of PVR is based on pressure divided by flow, and flow is proportional to $\mathrm{VO}_{2}$ using the Fick principle, an erroneously high $\mathrm{VO}_{2}$ results in a systematic underestimation of PVR. This has also been shown to be the case in other studies that have examined the effect of using an estimated $\mathrm{VO}_{2}$ versus a measured $\mathrm{VO}_{2} \cdot{ }^{6,8}$

We also show that there is no hemodynamic parameter that can be substituted for direct measurement of $\mathrm{VO}_{2}$. Although there was correlation with $\mathrm{cO}_{2}$ in the RA and SVC against the indexed-measured $\mathrm{VO}_{2}$, this correlation probably tells us more about how the body responds in low cardiac output situations. Again, using the Fick principle $\left(\mathrm{VO}_{2}=\mathrm{Qv} \times\left(\mathrm{cO}_{2 \mathrm{Ao}}-\mathrm{cO}_{2 \mathrm{SV}}\right)\right.$ a decrease in $\mathrm{cO}_{2 \mathrm{~Sv}}$ represents more oxygen extraction. If cardiac output is relatively fixed, the only way to increase $\mathrm{VO}_{2}$ is to increase oxygen extraction at the tissue level, resulting in a lower venous $\mathrm{O}_{2}$.

We did not find correlation between the measured $\mathrm{VO}_{2}$ and BSA, as was present when we looked at the Krovetz and Goldbloom ${ }^{1}$ prediction of $\mathrm{VO}_{2}$ against BSA. Prediction of $\mathrm{VO}_{2}$ based on height and weight is clearly oversimplified because it is influenced by other variables. $\mathrm{Li}$ and colleagues ${ }^{21}$ demonstrated that increases arterial in arterial partial pressure of carbon dioxide $\left(\mathrm{PaCO}_{2}\right)$ from 35 to $55 \mathrm{~mm} \mathrm{Hg}$ resulted in 
a significant decrease in $\mathrm{VO}_{2}$ from $146 \mathrm{~mL} / \mathrm{min} / \mathrm{m}^{2}$ to 126 $\mathrm{mL} / \mathrm{min} / \mathrm{m}^{2}$ in postoperative BDCPA patients.

The formula by Lafarge and Miettinen ${ }^{2}$ attempts to compensate for some of those variables with the incorporation of heart rate into its predictive formula. We did not record heart rate prospectively at the time of our data acquisition, and its retrospective assessment is not possible because heart rate can vary significantly, even under general anesthesia. However, this formula has been shown to underestimate $\mathrm{VO}_{2}$ when evaluated in this patient population. ${ }^{8}$

The results of our comparison of a measured $\mathrm{VO}_{2}$ by thermodilution cardiac output to a predicted $\mathrm{VO}_{2}$ by Krovets and Goldbloom ${ }^{1}$ were similar to the results of a comparison by $\mathrm{Li}$ and colleagues ${ }^{7}$ between measured $\mathrm{VO}_{2}$ by respiratory mass spectrometry with 4 predictive formulas (Lindahl, ${ }^{4}$ Wessel and associates, ${ }^{5}$ Lundell and colleagues, ${ }^{3}$ and Lafarge and Miettinen ${ }^{2}$ ). Their study was performed in ventilated children with congenital heart disease. Both studies demonstrate that the predictive formulas tend to overestimate lower $\mathrm{VO}_{2}$ and underestimate higher $\mathrm{VO}_{2}$ (Figure 1). In our study, we excluded patients with large APCs from our assessment. It is well known that APCs are often present, and it is difficult to quantify APC flow angiographically. Grosse-Wortmann and colleagues ${ }^{22}$ recently demonstrated the quantification of APC flow by MRI. They found that APC flow contributed as much as $46 \%$ of $\mathrm{Q}_{\mathrm{P}}$ in patients with a BDCPA as measured by MRI. Although this may seem problematic, our formula derives $\mathrm{Q}_{\mathrm{P}}$ based on pulmonary venous $\mathrm{cO}_{2}$ so that $\mathrm{APC}$ flow is accounted for. As such, APC flow is not a concern in assessing $\mathrm{Q}_{\mathrm{p}}$. Potential for error remains, however, if the measured pulmonary venous $\mathrm{cO}_{2}$ has been altered by flow from a systemic vein to a pulmonary venous connection or regional pulmonary disease.

It should be noted that the thermodilution method must be applied with caution in patients with severe atrioventricular or aortic valve regurgitation. Although some studies have failed to find an effect on thermodilution-derived cardiac output compared with the Fick method in patients with severe tricuspid valve regurgitation, ${ }^{23}$ other studies have found that the thermodilution method underestimates cardiac output in this situation. ${ }^{24-26}$ None of our patients had more than moderate valvar regurgitation. However, one must keep in mind that if this method is applied in patients with significant valvar regurgitation, a potential source of error is introduced.

One final potential limitation of this technique is that it in these circulations, it is not possible to obtain a pure systemic or pulmonary venous oxygen saturation. We attempted to overcome this with careful positioning of the sampling catheter, as described earlier. Specifically, the pulmonary venous sample was taken from a posterior location in the pulmonary venous atrium, close to the orifice of the PVs, to sample only pulmonary venous return. In our series, the pulmonary venous saturations were all $95 \%$ or more, suggesting little systemic venous contamination. However, contamination of systemic or pulmonary venous samples should be regarded as another potential source of error when using this method.

\section{CONCLUSIONS}

The reliance on an estimated $\mathrm{VO}_{2}$ in the assessment of PVR in patients with BDCPA prior to the Fontan operation provides erroneous results. The method presented for calculating $\mathrm{VO}_{2}$ is simple and can be done in centers where other methods of measuring $\mathrm{VO}_{2}$ directly are not readily available, by incorporating thermodilution cardiac output as part of the routine pre-Fontan cardiac catheterization. In this era, there are few instances when the Fontan procedure is not offered on the basis of risk. However, it remains useful to assess patients' risk and to evaluate outcomes in relation to their risk. Because assessing PVR remains one of the primary reasons for cardiac catheterization in this group of patients, this method provides a more precise assessment of PVR and can be used with ease.

We thank Colleen O'Connell, PhD, from the IWK Perinatal Epidemiology Research Unit, for her assistance with statistical analysis.

\section{References}

1. Krovets LG, Goldbloom S. Normal standards for cardiovascular data 1: examination of the validity of cardiac index. Johns Hopkins Med J. 1972;130: 174-86.

2. Lafarge CG, Miettinen OS. The estimation of oxygen consumption. Cardiovasc Res. 1970;4:23-30.

3. Lundell BPW, Casas ML, Wallgren CG. Oxygen consumption in infants and children during heart catheterization. Pediatr Cardiol. 1996;17:207-13.

4. Lindahl SGE. Oxygen consumption and carbon dioxide elimination in infants and children during anesthesia and surgery. Br J Anaesth. 1989;62:70-6.

5. Wessel HU, Rorem D, Muster AJ, Acevedo RE, Paul MH. Continuous determination of oxygen uptake in sedated infants and children during cardiac catheterization. Am J Cardiol. 1969;24:376-85.

6. Laitinen PO, Rasanen J. Measured versus predicted oxygen consumption in children with congenital heart disease. Heart. 1998;80:601-5.

7. Li J, Bush A, Schulze-Neick I, Penny DJ, Redington AN, Shekerdemian LS. Measured versus estimated oxygen consumption in ventilated patients with congenital heart disease: the validity of predictive equations. Crit Care Med. 2003; 31:1235-40

8. Shanahan CL, Wilson NJ, Gentles TL, Skinner JR. The influence of measured versus assumed uptake of oxygen in assessing pulmonary vascular resistance in patients with a bidirectional Glenn anastomosis. Cardiol Young. 2003;13: 137-42.

9. Peyton PJ, Chong SW. Minimally invasive measurement of cardiac output during surgery and critical care: a meta-analysis of accuracy and precision. Anesthesiology. 2010;113:1220-35.

10. Cowley AJ, Murphy DT, Stainer K, Murphy J, Hampton JR. A non-invasive method for measuring cardiac output: the effect of Christmas lunch. Lancet. 1986;328:1422-4.

11. Wippermann CF, Huth RG, Schmidt FX, Thul J, Betancor M, Schranz D. Continuous measurement of cardiac output by the Fick principle in infants and children: comparison with the thermodilution method. Intensive Care Med. 1996;22: 467-77.

12. Choussat A, Fontan F, Besse P. Selection criteria for Fontan's procedure. In: Anderson RH, Shinebourne EA, eds. Pediatric cardiology. Edinburgh: Churchil Livingstone; 1977:559-66. 
13. Freedom RM, Mawson JB, Yoo SJ, Benson LN. Chapter 39. Criteria for Fontans operation. In: Freedom RM, Mawson JB, Yoo SJ, Benson LN, eds. Congenital heart disease: textbook of angiocardiography. Vol. 2. Armonk, NY: Futura Publishing; 1997:1171-2.

14. Hosein RBM, Clarke AJB, McGuirk SP, Griselli M, Stumper O, De Giovanni JV, et al. Factors influencing early and late outcome following the Fontan procedure in the current era. The "Two Commandments?" Eur J Cardiothorac Surg. 2007; 31:344-53.

15. Nakanishi T. Cardiac catheterization is necessary before bidirectional Glenn and Fontan procedures in single ventricle physiology. Pediatric Cardiol. 2005;26: 159-61.

16. Fogel MA. Is routine cardiac catheterization necessary in the management of patients with single ventricles across staged Fontan reconstruction? No! Pediatric Cardiol. 2005;26:154-8.

17. Mair DD, Hagler DJ, Puga FJ, Schaff HV, Danielson GK. Fontan operation in 176 patients with tricuspid atresia: results and a proposed new index for patient selection. Circulation. 1990;82:164-9.

18. Pizzaro C, Mroczek T, Gidding SS. Fontan completion in infants. Ann Thorac Surg. 2006;81:2243-9.

19. Malhotra SP, Ivy DD, Mitchell MB, Campbell DN, Dines ML, Miyamoto S, et al. Performance of cavopulmonary palliation at elevated altitude: midterm outcomes and risk factors for failure. Circulation. 2008;118: S177-81.
20. Yun TJ, Im YM, Jung SH, Jhang WK, Park JJ, Seo DM, et al. Pulmonary vascular compliance and pleural effusion duration after the Fontan procedure. Int J Cardiol. 2009;133:55-61.

21. Li J, Hoskote A, Hickey C, Stephens D, Bohn D, Holtby H, et al. Effect of carbon dioxide on systemic oxygenation, oxygen consumption, and blood lactate levels after bidirectional superior cavopulmonary anastomosis. Crit Care Med. 2005; 33:984-9.

22. Grosse-Wortmann L, Al-Otay A, Yoo SJ. Aortopulmonary collaterals after bidirectional cavopulmonary connection or Fontan completion: quantification with MRI. Circ Cardiovasc Imaging. 2009;2:219-25.

23. Gonzalez J, Delafosse C, Fartoukh M, Capderou A, Straus C, Zelter M, et al. Comparison of bedside measurement of cardiac output with the thermodilution method and the Fick method in mechanically ventilated patients. Crit Care. 2003; $7: 171-8$.

24. Cigarroa RG, Lange RA, Williams RH, Bedotto JB, Hillis LD. Underestimation of cardiac output by thermodilution in patients with tricuspid regurgitation. Am J Med. 1989;86:417-20.

25. Konishi T, Nakamura Y, Morii I, Himura Y, Kumada T, Kawai C. Comparison of thermodilution and Fick methods for measurement of cardiac output in tricuspid regurgitation. Am J Cardiol. 1992;80:538-9.

26. Heerdt PM, Blessios GA, Beach ML, Hogue CW. Flow dependency of error in thermodilution measurement of cardiac output during acute tricuspid regurgitation. J Cardiothorac Vasc Anesth. 2001;15:183-7. 